\section{Validity and reliability of Turkish version of "Paternal Antenatal Attachment Questionnaire”}

\section{"Paternal Antenatal Bağlanma Ölçeği”" nin Türkçe versiyonunun geçerlik ve güvenirlik çalışması}

\author{
Duygu Güleç Şatır ${ }^{1}$ \\ Oya Kavlak ${ }^{2}$
}

\begin{abstract}
Objective:The study was carry out in order to evaluate the validity and reliability of PaternalAntenatal Attachment Questionnaire.

Method: Research was made with 155 expectant fathers who attended routine pregnancy controls with their partners in a obstetric and gynecology clinic in Izmir, were literate, aged 18 or older and without any health risk of fetus. Data were collected by information form and Paternal-Antenatal Attachment Questionnaire by developed Condon in 1993. İnitially the language validity of the scale was made by using the translation-back translation method with five experts. The Turkish version of the scale was presented to the opinion of ten experts using Davis technique for the content validity and content validity index was calculated. Factor structure was tested.by exploratory and confirmatory factor analysis. In the confirmatory factor analysis, structural equation modelling fit indices were examined.
\end{abstract}

Findings: Content validity index of each item was determined to vary between .80-1.00. As a
Özet

Amaç: Araştırma "Paternal Antenatal Bağlanma Ölçeği”"nin geçerlik ve güvenirliğini incelemek amacıyla gerçekleştirilmiştir.

Yöntem: Araştırma İzmir'de bir kadın doğum kliniğine, eşleriyle birlikte rutin gebelik kontrollerine katilan, okuma yazma bilen, 18 yaş üzeri ve fetüste herhangi sağlık riski bulunmayan 155 baba adayı ile gerçekleştirilmiştir. Veriler sosyodemografik bilgi formu ve Condon tarafindan 1993 tarihinde geliştirilmiş olan "Paternal Antenatal Bağlanma Ölçeği" ile toplanmıştır. Öncelikle beş uzman ile çeviri-geri çeviri yöntemi kullanılarak ölçeğin dil geçerliği yapilmıştır. Türkçe son hali oluşturulmuş ölçek kapsam geçerliliği için Davis tekniği kullanılarak on alan uzmanın görüşüne sunulmuş ve kapsam geçerlik indeksi hesaplanmıştır. Açımlayıcı ve doğrulayıc faktör analizi ile ölçeğin faktör yapısı değerlendirilmiştir. Doğrulayıcı faktör analizi için yapısal eşitlik modeli uyum indeksleri incelenmiştir. Ölçeğin güvenirlik analizinde cronbach alfa güvenirlik katsayısı ve madde toplam kolelasyon değerleri hesaplanmıştır.

Bulgular: Kapsam geçerlik indeksi sonucu her

Bu araştırma 31 Ekim- 01 Kasım 2019 tarihleri arasında Bursa'da düzenlenen 2. Uluslararası 5. Ulusal Kültürlerarası Hemşirelik Kongresi'nde sözel bildiri olarak sunulmuştur.

1 Dr. Öğr. Üyesi, Ege Üniversitesi Hemşirelik Fakültesi, Kadın Sağlığı ve Hastalıkları Hemşireliği Anabilim Dalı, duygugulec50@hotmail.com (iD) Orcid ID: 0000-0002-0226-3985

2 Prof. Dr., Ege Üniversitesi Hemşirelik Fakültesi, Kadın Sağlı̆̆ı ve Hastalıkları Hemşireliği Anabilim Dalı, oya.kavlak@gmail.com (D) Orcid ID: 0000-0003-3242-5313 
Güleç Șatır, D., \& Kavlak, O. (2021). "Paternal Antenatal Bağlanma Ölçeği” nin Türkçe versiyonunun geçerlik ve güvenirlik çalışması. Journal of Human Sciences, 18(1), 1-11. doi:10.14687/jhs.v18i1.6047

result of exploratory factor analysis, a two-factor structure explaining $36.54 \%$ of the total variance of the scale was determined. Factor loads vary between $0.41-0.84$ in the one dimension and $0.30-0.82$ in the another dimension. Confirmatory factor analysis showed that this two-factor structure was appropriate (RMSEA 0.044, GFI 0.912, AGFI $0.880 \chi^{2} / \mathrm{df}$ ise $1.298(\mathrm{p}=0.025)$. The Cronbach's alpha value of scale was 0.79 .

Conclusions: The two-factor structure of the scale, as "attachment quality" and "time spent of attachment mode" is valid and reliable for the use of expectant fathers' Turkish society.

Keywords: Father; pregnancy; attachment; questionnaire; factor analysis.

(Extended English summary is at the end of this document) bir maddenin 0,80-1,00 arasında değiştiği belirlenmiştir. Açımlayıcı faktör analizi ile ölçeğin toplam varyansının \% 36.54'ünü açiklayan iki faktörlü bir yapı belirlenmiştir. Faktör yükleri ilk boyutta $0.41-0.84$ arasında değişirken diğer boyutta 0.30-0.82 değerleri arasında değişmektedir. Doğrulayıcı faktör analizi bu iki faktörlü yapının uygun olduğunu göstermiştir (RMSEA 0.044, GFI 0.912, AGFI $0.880 \chi 2 / \mathrm{df}$ ise $1.298(\mathrm{p}=0.025)$. Ölçeğin Cronbach's Alpha değeri 0.79 bulunmuştur.

Sonuç: "Bağlanma kalitesi" ve "bağlanmaya yönelik geçirilen zaman" olmak üzere iki faktörlü yapidan oluşan ölçek Türk toplumunda bebek bekleyen baba adaylarının kullanilması için geçerli ve güvenilirdir.

Anahtar Kelimeler: Baba; gebelik; bağlanma; anket; faktör analizi.

\section{Giriş}

Birçok kültürde olduğu gibi, Türk toplumunda da evin geçimini sağlamakla tanımlanan geleneksel babalık rolü algısı son yıllarda annelerin çalışma hayatına girmesi, modernleşme, sanayileşme, küreselleşme gibi toplumsal değişimlerle değişikliğe uğramıştır (Durmaz et al., 2016; Finley et al., 2008; Tinkew et al., 2006). Özellikle batı toplumlarında babaların bakım verici rolleri gelişmektedir (Xue et al.,2018). Türk toplumunda da babalar artık çocuklar1 ile daha fazla etkileşimde bulunmakta, çocuğun bakımı, eğitim hayatı ve yaşamına daha fazla katılmaktadır (Biber, 2016; Korkmaz ve Derman, 2014; Şahin vd., 2017).

Baba çocuk ilişkisinin çocukların ileriki dönemde zihinsel, sosyal ve psikolojik gelişimleri etkilediğine yönelik çalışma sonuçları literatürde yer almaktadır (Grossmann et al., 2002; Sarkadi et al., 2008; Opondo et al., 2016). Bununla birlikte babaların çocukları ile olan etkileșimi de annelerde olduğu gibi gebelik döneminde başlamaktadır (Brandon et al., 2009; Condon, 1985; Hall et al., 2014). Gebelik süresince babalar da doğacak bebeklerine yönelik hislere ve düşüncelere sahiptir. Bu süreçte doğmamış bebeklerine az ya da çok bağlanırlar ve kendilerini ebeveynliğe ve bebekle geçirecekleri sürece hazırlarlar (Habib and Lancaster 2006, May and Fletcher 2013).

Prenatal bağlanma ebeveynin fetüse yönelik duygu, düşünce ve tutumları şeklinde tanımlanmaktadır (Brandon et al., 2009). Condon'a göre, paternal fetal bağlanma çocuk hakkında bir tutum ya da inançtan ziyade, doğmamış çocuk için öznel bir sevgi duygusudur ve erkeğin erken ebeveynlik deneyiminin merkezinde yer alır. Gebelik süresince babanın fetüse bağlanması ile ilgili sınırlı çalışma sonuçları mevcuttur. Annelerle karşılaştırma yapılan çalşmalarda genellikle fetüse bağlanma babalarda daha düşük bulunmuştur (Lorensen et al., 2004; Ustunsoz et al., 2010). Condon ve arkadaşlarının(2013) çalışmasında paternal antenatal bağlanma puanlarının doğum sonrası 6. ve 12. aydaki bağlanma puanları arasında güçlü ve anlamlı bir ilişki olduğunu belirtmiştir. Righetti ve ark. (2005) ultrason muayenesinden sonra babaların bağlanma puanlarının değişmediğini, Armstrong (2002) prenatal kayıp öyküsünün paternal prenatal bağlanmayı etkilemediğini, Kunkel ve Doan (2003) ise depresyon düzeyinin gebelikteki bağlanma puanlarını etkilemediğini belirtmiştir.

Gebelik dönemi sağlıklı yaşam olaylarından biri olmasına rağmen, bu dönemde bebek bekleyen babaların, ebeveynlik rolüne alışamama, doğum, doğum sonrası bebek bakımı endişesi gibi sebeplerden dolayı stres düzeyleri artmaktadır (Genesoni and Tallandini 2009; Philpott vd, 2017). 
Güleç Șatır, D., \& Kavlak, O. (2021). "Paternal Antenatal Bağlanma Ölçeği” nin Türkçe versiyonunun geçerlik ve güvenirlik çalışmas1. Journal of Human Sciences, 18(1), 1-11. doi:10.14687/jhs.v18i1.6047

Yaşanılan bu stresli süreç onların fetüse yönelik bağlanma duygusunun gelişmesinde problem oluşturabilir. Hemşireler doğuma hazırlık sinıfları gibi antenatal programlarda ve rutin kontrollerde babaların bebeklerine bağlanmalarını, bağlanmayı etkileyen faktörleri değerlendirebilir, anormal durumlar1 saptayabilirler.

Babanın çocuk gelişimine etkisi bilinmesine rağmen ebeveyn fetüs ilişkisine yönelik çalışmalar daha çok annelere odaklanmıştır. Babalar ile ilgili yapılan çalışmalar ise daha çok postpartum dönemde ele alınmıştır. Sağlıklı baba-bebek ilişkisinin kurulmasının gebelik döneminde başladığ1 düşünüldüğünde beklenen bebeğe ilisskin duyguların ve bağlanmanın araştırılmasının önemli olduğu düşünülmektedir. Türkiye'de paternal antenatal bağlanmaya ilişkin daha fazla araştırmaya ihtiyaç vardır. Bu kapsamda bu çalısma ile Condon(1993)'un Paternal Antenal Bağlanma Ölçeği'nin Türk toplumuna uyarlanması amaçlanmıştır.

\section{Gereç Yöntem}

Araştırmanın tipi, yeri ve zamanı: Metodolojik tipte olan bu araştırma Ocak- Haziran 2018 tarihlerinde İzmir'de özel bir kadın doğum kliniğinde gerçekleştirilmiştir.

Araştırmanın evreni ve örneklemi: Araştırmanın evrenini Ocak- Haziran 2018 tarihleri arasında İzmir'de yer alan kadın doğum kliniğine eşi ile birlikte rutin ultrason muayenesine gelen babalar oluşturmuştur. Ölçek uyarlama çalsşmalarında faktör analizinin gerçekleştirilmesi için örneklem sayısının ölçeğin madde sayısının 5-10 katı arasında olması beklenmektedir (Tavşancıl, 2002; Büyüköztürk, 2002). Bu kapsamda 16 maddeden oluşan Paternal Antenatal Bağlanma Ölçeği için ulaşılması gereken sayı 80-160 arasında değişmektedir. Araştırmaya en az ilkokulu mezunu, onsekiz yaş ve üzeri, gebelikle ilgili anne ve fetüste herhangi sağlık riski bulunmayan, çoğul gebelik olmayan, yardımc1 üreme tekniği ile oluşmamış, araştırmaya katılmaya gönüllü 160 baba adayı oluşturmuştur, daha sonra verilerin incelenmesi sırasında beş verinin hatalı ve eksik doldurulduğu fark edilerek araştırma dışı bırakılmış ve araştırma 155 baba adayı ile tamamlanmıştur.

\section{Veri Toplama Yöntemi}

Araştırma verileri eşlerinin muayenesi öncesinde, kliniğin bekleme salonunda öz bildirime dayalı olarak toplanmıştır. Öncelikle baba adaylarına araştırma hakkında bilgi verilmiş, araştırmanın amacı açıklanmış ve onamları alınmıştır.

Araştırma verilerinin toplanmasında birey tanılama formu ve Paternal Antenatal Bağlanma Ölçeği Türkçe formu kullanılmıştır.

Birey tanılama formu babanın yaşı, eğitim düzeyi, mesleği, ekonomik durumu, evlilik süresi çocuk sayısı gibi sosyodemografik sorular ve gebelik haftası, fetüsün cinsiyeti gibi gebelikle ilgili soruları içermektedir.

Paternal Antenatal Bağlanma Ölçeği: Condon (1993) tarafindan geliştirilmiş, antenatal dönemde bebek bekleyen baba adaylarının fetüse ilişkin duygularını, tutumlarını ve davranışlarını ölçen ölçek 16 soru ve 2 alt boyuttan (bağlanma kalitesi ve bağlanmaya ilişkin geçirilen zaman) oluşmaktadır. Sorular 1 ve 5 puan arasında puanlanmakta, toplam bağlanma puanı 16-80 arasında değişmektedir. Puanlar arttıkça bağlanma da artmaktadır. Condon(1993) çalışmasında 112 baba adayına ölçeği uygulamış ve Cronbach alfa güvenirlik katsayısını 0,80 olarak saptamıştır.

Baba adaylanına muayene öncesi bekleme salonunda araştırma hakkında bilgi verilmiş, araştırmanın amacı açıklanmış ve onamları alınmıştır.

\section{Araştırmanın uygulanması, geçerlik ve güvenirlik çalışmaları Dil Geçerliliği}

Ölçeğin dil geçerliliğinde çeviri, geri çeviri yöntemi kullanılmıştır. İlk aşamada; ölçeğin İngilizce versiyonu, dil geçerliliği açısından bir birinden bağımsız, iki dil uzmanı ve üç hemşirelik alanından uzman toplam beş kişi tarafindan Türkçe'ye çevrilmiştir. Araştırmacılar tarafindan çeviriler tek tek incelenerek değerlendirilmiş ve en uygun ifadeli olanlar seçilerek Türkçe hali yapılandırılmıştır. Ölçeğin tekrar İngilizceye çevrilmesi başka bir dil uzmanı tarafından 
Güleç Șatır, D., \& Kavlak, O. (2021). "Paternal Antenatal Bağlanma Ölçeği” nin Türkçe versiyonunun geçerlik ve güvenirlik çalışması. Journal of Human Sciences, 18(1), 1-11. doi:10.14687/jhs.v18i1.6047

gerçekleştirilmiştir. Yapılan çeviri ile ölçeğin orjinali araştırmacılar tarafından karşılaştırılarak Türkçe yapının son şekli oluşturulmuştur.

\section{Kapsam Geçerliliğ̈i}

Ölçeğin Türkçe'ye çevrilmesinin ardından, Davis tekniği kullanılarak sorular hemşirelik alanında uzman ve ölçek geliştirme ve uyarlama konusunda deneyimli 10 kişinin görüşüne sunulmuştur (Yurdugül, 2005). Uzmanlar her bir sorunun anlaş1lırlığını, amaca uygunluğunu ve kültürel uygunluğunu incelemişler, her bir sorunun ölçme özelliğini değerlendirerek "uygun, madde gözden geçirilmeli; madde ciddi olarak gözden geçirilmeli, ve uygun değil”" şeklinde görüş belirtmişlerdir. Uzmanların verdikleri öneriler incelenmiş ve ölçeğin tümü tekrar gözden geçirilerek gereken düzeltmeler yapılmıştır.

Uzmanların görüşleri doğrultusunda uygun veya madde gözden geçirilmeli seçeneğini işaretleyenlerin sayısı, danışlan tüm uzman sayısına bölünmüş ve her sorunun kapsam geçerlilik indeksi (KGI) hesaplanmıştur. KGİ 0,80'in üzerinde ise ölçekte yer alan soruların kapsam geçerliliği sonucunun uygun olduğu şeklinde yorum yapılmaktadır (Polit et al., 2007; Delgado-Rico et al., 2012).

Dil geçerliliği ve kapsam geçerliliği sonrası son hali oluşturulan ölçek bebek bekleyen 20 baba adayına uygulanmış ve soruların açıklığı ve anlaşılırlığını değerlendirmeleri istenmiştir. Pilot çalışmada sorular anlaşlır bulunmuş ve herhangi bir düzeltme yapmadan veri toplama sürecine geçilmiştir.

\section{Araştırmanın Etik Boyutu}

Ölçeğin geçerlik güvenirliğinin yapılabilmesi için ölçeği geliştiren yazardan mail yolu ile izin alınmıştır. Araştırmanın yapılabilmesi için bir Üniversitenin etik kurul biriminden onay alınmıştır (B.30.2.EGE.0.82./21-278). Klinikten araştırmayı uygulamak için gerekli izin alınmıştır. Babalara araştırmanın amacı açıklanarak onamları alınmıştır.

\section{Verilerin Değerlendirilmesi}

Araştırma sonucunda ortaya çıan verilerin değerlendirilmesi IBM SPSS 22.0 software ve AMOS 22.0 istatistik programları ile gerçekleştirilmiştir. Tanıtıcı özellikler sayı yüzde olarak hesaplanmış, uzman görüşleri için KGİ hesaplanmıştur. Örneklem büyüklügünün yeterliğinin belirlenmesinde Kaiser-Meyer-Olkin (KMO) ve Bartlett Küresellik Testi hesaplanmıştır. Faktör yapısını ve geçerliğini belirlemek için temel bileşen analizi tekniği ile promax rotasyonlu açıklayıcı faktör analizi ve uyum iyiliği değerlerini incelemek amacıyla doğrulayıcı faktör analizi yapılmıştır. Güvenirlik analizi olarak, ölçek maddelerinin iç tutarlı̆̆ının belirlenmesinde Cronbach alfa $(\alpha)$ güvenirlik katsayısı ve madde toplam korelasyonları hesaplanmıştır.

\section{Baba adaylarının tanıtıcı bulguları}

\section{BULGULAR}

Tablo 1. Tanıtıcı özellikler

\begin{tabular}{|l|c|c|}
\hline Tanıtıcı özellikler & Sayı & Yüzde \\
\hline Yaş ortalama & \multicolumn{2}{|c|}{$32,9 \pm 4,8$} \\
\hline Evlilik yılı ortalama & \multicolumn{2}{|c|}{$4,7 \pm 3,7$} \\
\hline Eğitim düzeyi & \\
Illköğretim & & 13,5 \\
Lise & 21 & 24,5 \\
Üniversite & 38 & 51,6 \\
Lisansüstü & 80 & 10,4 \\
\hline
\end{tabular}


Güleç Şatır, D., \& Kavlak, O. (2021). "Paternal Antenatal Bağlanma Ölçeği” nin Türkçe versiyonunun geçerlik ve güvenirlik çalışması. Journal of Human Sciences, 18(1), 1-11. doi:10.14687/jhs.v18i1.6047

\begin{tabular}{|c|c|c|}
\hline $\begin{array}{l}\text { Çalışma durumu } \\
\text { Çalışan } \\
\text { Çalışmayan }\end{array}$ & $\begin{array}{l}152 \\
3\end{array}$ & $\begin{array}{l}98,1 \\
1,9\end{array}$ \\
\hline $\begin{array}{l}\text { Ekonomik durum algisı } \\
\text { Yeterli } \\
\text { Kismen yeterli } \\
\text { Yetersiz }\end{array}$ & $\begin{array}{l}93 \\
55 \\
7\end{array}$ & $\begin{array}{l}60,0 \\
35,5 \\
4,5\end{array}$ \\
\hline $\begin{array}{l}\text { Fetüsün cinsiyeti } \\
\text { Erkek } \\
\text { K1z } \\
\text { Belli değil }\end{array}$ & $\begin{array}{l}56 \\
70 \\
29\end{array}$ & $\begin{array}{l}36,1 \\
45,2 \\
18,7\end{array}$ \\
\hline $\begin{array}{l}\text { Trimester } \\
1 \\
2 \\
3\end{array}$ & $\begin{array}{l}13 \\
53 \\
79\end{array}$ & $\begin{array}{l}14,8 \\
34,2 \\
51,0\end{array}$ \\
\hline $\begin{array}{l}\text { Gebeliğin planlı olma durumu } \\
\text { Evet } \\
\text { Hayır }\end{array}$ & $\begin{array}{l}129 \\
26\end{array}$ & $\begin{array}{l}83,2 \\
16,8\end{array}$ \\
\hline $\begin{array}{l}\text { Babalık deneyimi } \\
\text { İlk kez } \\
2 \text { ve üzeri }\end{array}$ & $\begin{array}{l}96 \\
59\end{array}$ & $\begin{array}{l}38,1 \\
61,9\end{array}$ \\
\hline
\end{tabular}

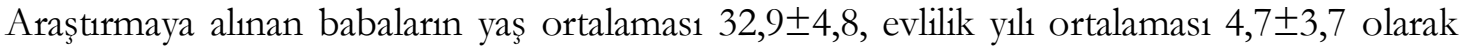
saptanmıştır. Babaların büyük çoğunluğu $(\% 51,6)$ üniversite mezunu ve $\% 38,1$ 'inin ilk babalık deneyimidir. Diğer tanıtıcı bilgilere ilişkin veriler Tablo 1'de gösterilmiştir.

\section{Paternal Antenatal Bağlanma Ölçeği ve alt boyutların puan ortalamaları}

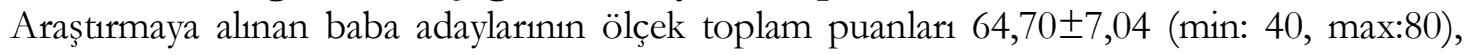
"bağlanma kalitesi" alt boyutu toplam puanları 28,2 $\pm 4,98$ (min: 14, max:40), "bağlanmaya yönelik geçirilen zaman" alt boyutu toplam puanlar1 ise 36,18 $\pm 3,26$ (min: 22, max:40) saptanmıştır (Alt boyutlar faktör analizi sonrası belirlenen alt boyutlardır).

\section{Ölçeğin geçerlik bulguları}

Kapsam geçerlik indeksi Davis tekniği ile hesaplanmıştır. Davis tekniğinde uzmanlarda “uygun” veya "madde gözden geçirilmeli” seçeneğini belirtenlerin sayıs1 10'a bölünerek maddeye yönelik "kapsam geçerlik indeksi" belirlenmiştir. İndekste 0,80 değeri sınır olarak belirtilmektedir. Kapsam geçerliği için 10 uzmanın ölçekte yer alan sorulara yönelik görüşleri incelendiğinde her bir sorunun KGI'si 0.80 'in üzerinde saptanmıştır.

Tablo 2. Paternal Antenatal Bağlanma Ölçeği Analiz Sonuçları

\begin{tabular}{|c|c|c|c|}
\hline Alt Boyutlar ve Ölçek Maddeleri & $\begin{array}{l}\text { Madde Toplam } \\
\text { Korelasyonu }\end{array}$ & $\begin{array}{l}\text { Döndürülmüş } \\
\text { Faktör Yükleri* }\end{array}$ & $\begin{array}{l}\text { Aç1klanan } \\
\text { Varyans }\end{array}$ \\
\hline \multicolumn{4}{|l|}{$\begin{array}{l}\text { Bağlanma Kalitesi } \\
\text { (Cronbach alfa katsayısı: 0.776) }\end{array}$} \\
\hline 1 & 0.580 & 0.835 & \multirow{5}{*}{$\% 26.543$} \\
\hline 2 & 0.624 & 0.536 & \\
\hline 3 & 0.495 & 0.729 & \\
\hline 4 & 0.437 & 0.767 & \\
\hline 5 & 0.373 & 0.407 & \\
\hline
\end{tabular}


Güleç Şatır, D., \& Kavlak, O. (2021). "Paternal Antenatal Bağlanma Ölçeği” nin Türkçe versiyonunun geçerlik ve güvenirlik çalışması. Journal of Human Sciences, 18(1), 1-11. doi:10.14687/jhs.v18i1.6047

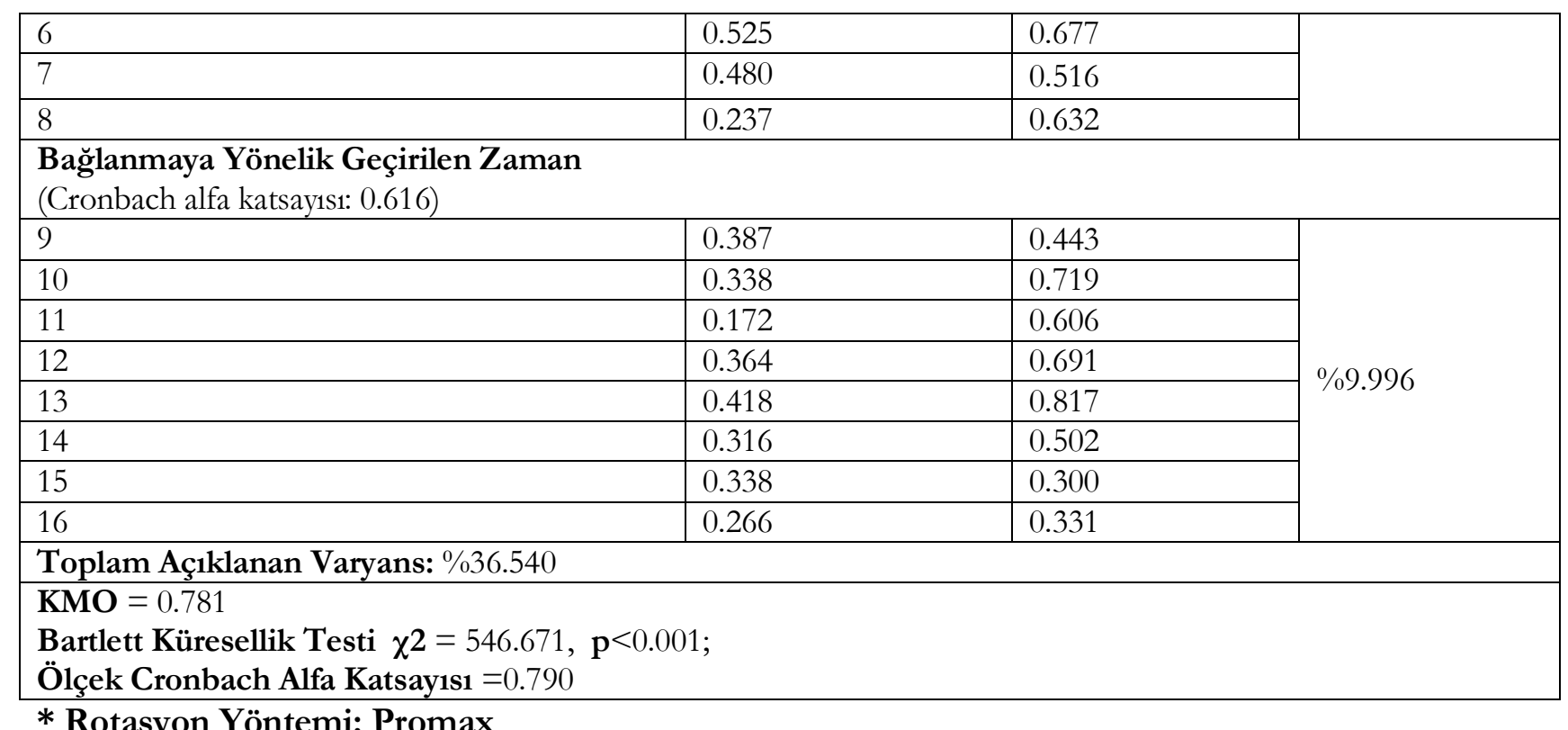

* Rotasyon Yöntemi: Promax

Ölçeğin yap1 geçerliliği çalışmasında verilerin açıklayıcı faktör analizi açısından uygun olup olmadığı KMO katsayısı ve Barlett Küresellik testi ile incelenmiștir. KMO değeri 0.781 olarak tespit edilmiştir. Barlett küresellik testi sonuçlarında ise ki-kare $=546.671(\mathrm{p}<0.001)$ değeri hesaplanmıştır (Tablo 2).

Yap1 geçerliği bulguları incelendiğinde; açıklayıcı faktör analizi sonucu ölçeğin 2 alt boyuttan meydana geldiği ve faktör yüklerinin ilk boyutta $0,84-0,41$ arasında değişirken ikinci boyutta 0,82 0,30 değerleri arasında değiştiği görülmüştür Faktörlerin varyansın toplam \%36,4'ünü açıkladığ1, açıklama yüzdelerinin 1 . faktör için \%26,5, 2. faktör için \%9,9 olduğu görülmüsstür (Tablo 2).

Tablo 3: Paternal Antenatal Bağlanma Ölçeğin İkincil Düzey Çok Faktörlü Doğrulayıcı Faktör Analizine İlişkin Yapısal Eşitlik Modeli Uyum İndeksleri

\begin{tabular}{|l|l|l|l|}
\hline $\begin{array}{l}\text { Uyum İyiliği } \\
\text { İndeksleri }\end{array}$ & $\begin{array}{l}\text { Araştırma Uyum } \\
\text { Değerleri }\end{array}$ & \multicolumn{2}{|c|}{ Referans değerleri* } \\
\hline RMSEA & 0.044 & $0 \leq \mathrm{RMSEA} \leq 0,05$ & İyi uyum \\
\hline CFI & 0.934 & $>0,90$ & Kabul edilebilir uyum \\
\hline GFI & 0.912 & $>0,90$ & Kabul edilebilir uyum \\
\hline AGFI & & & Kabul edilebilir uyum \\
\hline CMIN/df & 1.298 & $>0,85$ & İi uyum \\
\hline P değeri & 0.025 & $0 \leq 0,05 \leq 2$ & Kabul edilebilir uyum \\
\hline
\end{tabular}

* Schermelleh-Engel et al., 2003, Çapık 2014, Erkorkmaz vd., 2013 


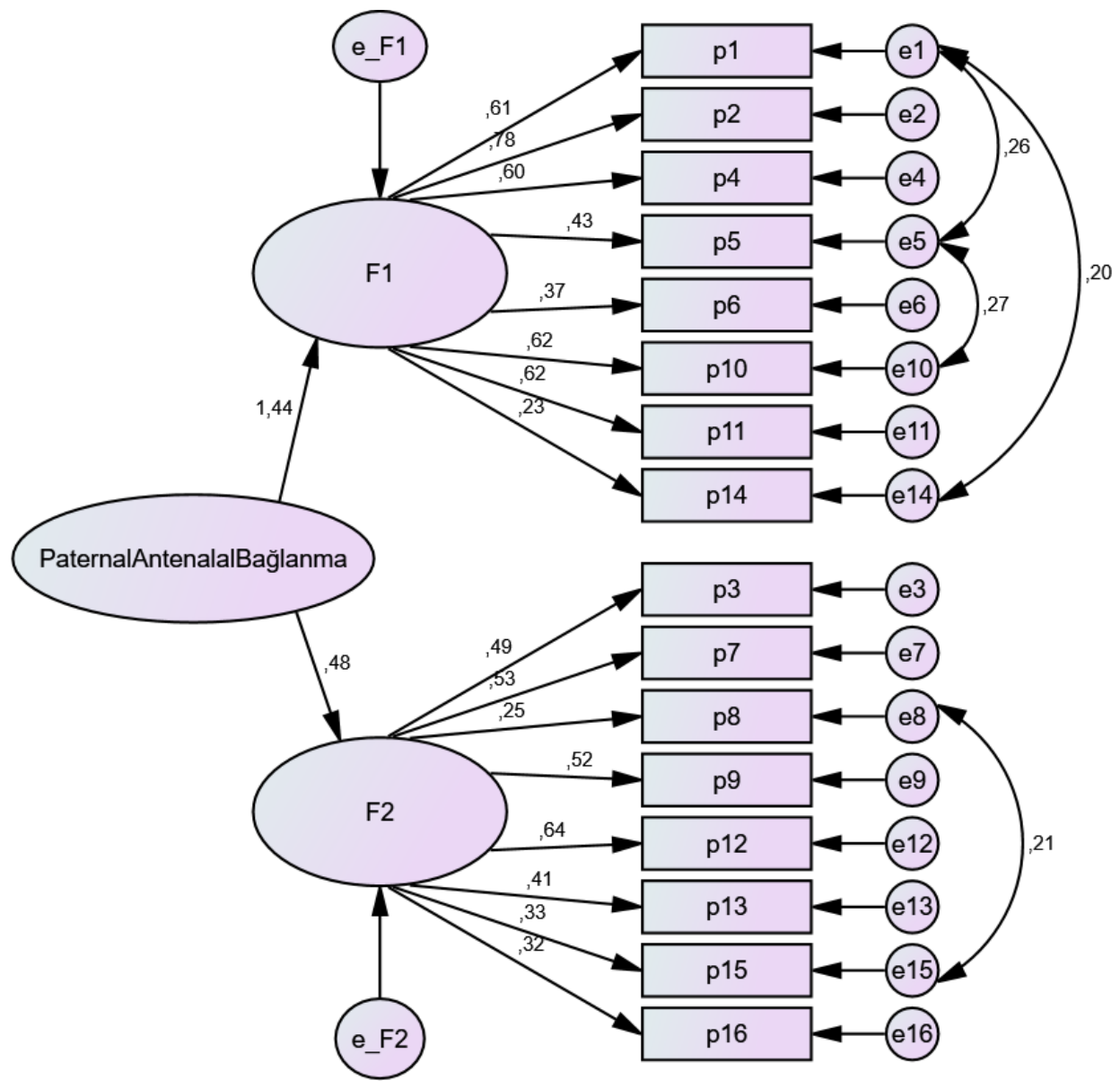

Şekil 1: Paternal Antenalal Bağlanma Ölçeğin İkincil Düzey Çok Faktörlü Doğrulayıc1 Faktör Analizine İlişkin Yapısal Eşitlik Modeli

Doğrulayıcı faktör analizi ile 16 madde, 2 alt boyuttan oluşan ölçeğin Ki-Kare uyum testi sonucuna göre p-değeri=0.025 düzeyinde anlamlı olduğu saptanmıştr. Ayrıca ölçeğin uyum iyiliği indekslerine bakıldığında; Yaklaşık Hataların Ortalama Karekökü (RMSEA) 0.044, Uyum İyiliği İndeksi (GFI) 0.912, Düzeltilmiş Uyum İyiliği İndeksi (AGFI) 0.880 ve ki-karenin serbestlik derecesine oranı $\left(\chi^{2} / \mathrm{df}\right)$ ise $1.298(\mathrm{p}=0.025)$ değerleri saptanmıştur. Elde edilen verilerin bu model için ne derece uygun olduğunu gösteren uyum indeksleri Tablo 3 'de gösterilmiştir. Doğrulayıc1 faktör analizi ile doğrulanan modelin Path diyagramı Şekil 1'de gösterilmiştir.

\section{Ölçeğin güvenirlik analizi bulguları}

Ölçek maddelerinin toplam korelasyonları 8. madde dışında diğer maddelerin 0.20'nin üzerinde bulunmuştur. Sekizinci maddenin madde toplam korelasyonu 0.17 bulunmuştur. Ölçeğin Cronbach alfa güvenirlik katsayısı 0,79 , alt boyutların Cronbach alfa güvenirlik katsayıları ise 1. alt boyut 0,78, 2. alt boyut: 0,62 olarak saptanmıştır (Tablo 2).

\section{TARTIŞMA}

Paternal Antenatal Bağlanma Ölçeği’nin geçerliliği kapsam geçerliği, AFA ve DFA ile değerlendirilmiş olup, güvenilirliği ise iç tutarllık analizleri ve madde toplam korelasyonu ile araștırılmıștur.

Kapsam geçerliliğini belirlemek için uzman görüşüne başvurulmuş ve KGİ ölçülmüştür. Araştırma sonucuna göre soruların KGİ değerleri 0,8-1,0 arasında değişmektedir. Kapsam 
Güleç Șatır, D., \& Kavlak, O. (2021). "Paternal Antenatal Bağlanma Ölçeği” nin Türkçe versiyonunun geçerlik ve güvenirlik çalışması. Journal of Human Sciences, 18(1), 1-11. doi:10.14687/jhs.v18i1.6047

geçerliliğinde 0,80 değeri sınır olduğu göz önünde bulundurulduğunda (Davis, 1992). Ölçekteki her bir soruya ilişkin KGI’’inin yüksek ve kapsam geçerliliğinin yeterli olduğu söylenebilir.

Kültürel uyarlama çalşmalarında yapı geçerliliğini değerlendirmek için faktör analizi yapılmaktadır. Ölçeğin faktör analizi açısından uygun olup olmadığı ise KMO değeri ve Barlett's küresellik testi ile değerlendirilmektedir. KMO değerinin 0.60 'n üstünde ve Barlett küresellik testinin anlamlı çıkması verilerin faktör analizi açısından yeterli olarak değerlendirilmektedir (Büyüköztürk, 2002). KMO değeri 0.781, olarak hesaplanmış, Barlett küresellik testi sonuçları ise kikare $=546.671 ; \mathrm{p}<0.001$ bulunmuştur. Bu sonuca göre örneklem büyüklüğü "iyi”" seviyelerine yakın olarak değerlendirilmiştir.

Yap1 geçerliliğini değerlendirmek için öncelikle açımlayıcı faktör analizi ile ölçeğin kaç faktörden oluştuğu değerlendirilmiştir. Paternal Antenatal bağlanma ölçeğinin orijinal versiyonu iki faktörlü bir yapıdan oluşmaktadır. Faktörler varyansın toplam \%36,4’ünü açıklamaktadır. Ölçeğin İtalyanca versiyonunda da benzer șekilde faktörler varyansın toplam \%34'ünü açıklamıştır (Della Vedova, 2017). Bu sonuca göre, Türkçeye çevrilen yapının orijinalindeki gibi iki faktörden meydana geldiği, ancak bu iki faktörü oluşturan maddeler Condon (1993)'un orijinal ölçeği geliştirdiği çalışmasındaki iki faktörde yer alan maddelerle aynı bulunmamıştır. Ölçeğin İtalyan uyarlanmasında da maddeler farklı şekilde faktörlere dağılım göstermiştir (Della Vedova and Burro 2017). Üç farklı kültürde de maddelerin farklı boyutlarda yer almasını kültürel olarak babaların gebelikte fetüse yönelik duygularının ve bağlanmalarının farklı olabileceğinden kaynaklandığını düşündürmüştür.

Ölçeğin DFA sonuçlarına göre ise ölçeğin uyum iyiliği indeksleri incelendiğinde; RMSEA 0.044, $\chi 2$ df ise 1.298, GFI 0.912, CFI 0.934, AGFI 0.880, p değeri=0.025 değerleri bulunmuştur. Literatürde, uyum iyiliği indeksi değerlerinden RMSEA'nın 0.05 'ten, $\chi 2 / \mathrm{df}$ nin 2 den küçük olmasının modelin iyi uyuma sahip olduğunu gösterdiği belirtilmektedir. Ayrıca, GFI ve CFI 'nın 0,90'in üzerinde, AGFI'nın 0,85'in üzerinde, $\mathrm{p}$ değerinin ise 0,05 'ten küçük olmasının modelin kabul edilebilir uyum indeksine sahip olduğu belirtilmektedir (Schermelleh-Engel et al., 2003; Çapık 2014; Erkorkmaz vd., 2013). Bu doğrultuda bu ölçek DFA uyum indeksi değerleri iyi uyum ve kabul edilebilir uyum şeklinde yorumlanmıştır.

Ölçek güvenirlik analiz sonuçları incelendiğinde madde-toplam korelasyon katsayılarının 0,17 ile 0,62 arasında olduğu saptanmıştır. Literatürde bu değerin 0.20 ve üzerinde olması beklenmektedir (Büyüköztürk, 2015). Sadece bir maddenin 0,17 olarak saptandığ1 ve madde çıkarıldığında alfa değerinde yükselme olmadığı için ölçeğin orijinal yapısının korunması açısından ilgili madde ölçekten çıkarılmamıştır (Özdamar, 2004).

Diğer güvenirlik analizi sonucu olarak Cronbach alfa değerinin 0,00-1,00 değerleri arasında olduğu ve 1,00'e yaklaştıkça güvenirliğinin de yükseldiği, 0,70’in üzerindeki değerlerin iyi ve kabul edilebilir olduğu belirtilmektedir (Kılıç, 2016). Bu araştırma sonucunda ölçeğin toplam Cronbach alfa katsayısı 0,79 olarak saptanmış ve güvenilir olduğu ortaya çıkmıştır.

\section{SONUÇ}

"Bağlanma kalitesi” ve "bağlanmaya yönelik geçirilen zaman” olmak üzere iki faktörlü yapıdan oluşan ölçek Türk toplumunda bebek bekleyen baba adaylarının kullanılması için geçerli ve güvenilirdir. Gebelik döneminde babanın fetüse olan duygularını, bağlanma durumunu ve etkileyen faktörleri değerlendirmek üzere araştırmalarda kullanılabilir.

\section{KAYNAKLAR}

Armstrong, D.S.(2002). Emotional distress and prenatal attachment in pregnancy after perinatal loss. J Nurs Scholarsh, 34(4),339-345.

Biber, K. (2016). Perceptions of father involvement among Turkish fathers with pre-school children. Journal of Education and Training Studies, 4(6), 115-126.

Brandon, A., Pitts, S., Denton, W., Stringer, A., Evans, H.(2009). A history of the theory of prenatal attachment. J Prenat Perinat Psychol Health, 23(4), 201-222. 
Güleç Şatır, D., \& Kavlak, O. (2021). "Paternal Antenatal Bağlanma Ölçeği” nin Türkçe versiyonunun geçerlik ve güvenirlik çalışması. Journal of Human Sciences, 18(1), 1-11. doi:10.14687/jhs.v18i1.6047

Büyüköztürk, Ş.(2002) Faktör analizi: Temel kavramlar ve ölçek geliştirmede kullanımı. Kuram ve Uygulamada Ë̈itim Yönetimi Dergisi, 32:470-83.

Condon JT (1995). The parental-foetal relationship: A comparison of male and female expectant parents. J Psychosom Obstet Gynecol,4(4),271-284.

Condon, J. T. (1993). The assessment of antenatal emotional attachment: development of a questionnaire instrument. British Journal of Medical Psychology, 66(2), 167-183.

Condon, J., Corkindale, C., Boyce, P., \& Gamble, E. (2013). A longitudinal study of father-to-infant attachment: antecedents and correlates. Journal of Reproductive and Infant Psychology, 31(1), 1530 .

Çapık, C. (2014). Geçerlik ve güvenirlik çalışmalarında doğrulayıcı faktör analizinin kullanımı. Anadolu Hemsirelike ve Sağhk Bilimleri Dergisi, 17(3), 196-205

Davis, L.L.(1992). Instrument review: Getting the most from a panel of experts. Applied Nursing Research, 5(4): 194-197.

Delgado-Rico, E., Carrctero-Dios, H., Ruch, W. (2012). Content validity evidences in test development: An applied perspective. Int J Clinic Health Psych, 12: 449-459.

Della Vedova, A. M., Burro, R. (2017). Surveying prenatal attachment in fathers: The Italian adaptation of the Paternal Antenatal Attachment Scale (PAAS-IT). Journal of reproductive and infant psychology, 35(5), 493-508.

Durmaz, G. B., Baş, N. G.,Gümüş, F. (2016). Father's perceptions of their role in fathers with babies aged between 4 and 12 months in Turkey. Newborn and Infant Nursing Reviews,16(3), 115-118.

Erkorkmaz, Ü., Etikan, İ., Demir, O., Özdamar, K., Sanisoğlu, S. Y. (2013). Doğrulayıc1 faktör analizi ve uyum indeksleri. Turkiye Klinikleri Journal of Medical Sciences, 33(1), 210-223.

Finley, G.A., Mira, S.D., Schwartz, S.J.(2008). Perceived paternal and maternal involvement: factor structures, mean differences, and parental roles. Fathering, A Journal of Theory, Research, and Practice about Men as Fathers, 6(1), 62-82

Genesoni, L., Tallandini, M.A.(2009). Men's psychological transition to fatherhood: an analysis of the literature, 1989-2008. Birth, 36(4),305- 18.

Grossmann, K., Grossmann, K. E., Fremmer-Bombik, E., Kindler, H., Scheuerer-Englisch, H., Zimmermann, A. P.(2002). The uniqueness of the child-father attachment relationship: Fathers' sensitive and challenging play as a pivotal variable in a 16-year longitudinal study. Social Development, 11(3),307-311

Habib, C., \& Lancaster, S. (2006). The transition to fatherhood: Identity and bonding in early pregnancy. Fathering: A Journal of Theory, Research, and Practice about Men as Fathers, 4(3), 235253

Hall, R. A. S., De Waard, I. E. M., Tooten, A., Hoffenkamp, H. N., Vingerhoets, A. J. J. M., \& Van Bakel, H. J. A. (2014). From the father's point of view: How father's representations of the infant impact on father-infant interaction and infant development. Early Human Development, 90(12), 877-883.

Kilıç, S. (2016). Cronbach'ın alfa güvenirlik katsayısı. Journal of Mood Disorders, 6(1), 47-48.

Korkmaz, N. H., Derman, M. T. (2014). Opinions of play in turkish fathers. Procedia-Social and Behavioral Sciences, 141, 1182-1186.

Kunkel, G., Doan H (2003). Fetal attachment and depression: Measurement matters. Journal of Prenatal \& Perinatal Psychology \& Health, 18(2), 149-166.

Lorensen, M, Wilson, ME, White, M.A. (2004). Norwegian families: Transition to parenthood. Health Care Women Int, 25(4):334-348.

May, C., Fletcher, R. (2013). Preparing fathers for the transition to parenthood: Recommendations for the content of antenatal education. Midwifery, 29(5), 474-478. 
Güleç Șatır, D., \& Kavlak, O. (2021). "Paternal Antenatal Bağlanma Ölçeği” nin Türkçe versiyonunun geçerlik ve güvenirlik çalışması. Journal of Human Sciences, 18(1), 1-11. doi:10.14687/jhs.v18i1.6047

Opondo, C., Redshaw, M., Savage-McGlynn, E., Quigley, M.A.(2016). Father involvement in early child-rearing and behavioural outcomes in their pre-adolescent children: evidence from the ALSPAC UK birth cohort. BMJ Open, 6;6,1-9

Özdamar, K (2004). Paket Programlar ile İstatistiksel Veri Analizi I. 5. Bask1, Kaan Kitabevi, Eskișehir

Philpott, L. F., Leahy-Warren, P., FitzGerald, S., \& Savage, E. (2017). Stress in fathers in the perinatal period: A systematic review. Midwifery, 55, 113-127.

Polit, D. F., Beck, C. T., \& Owen, S. V. (2007). Is the CVI an acceptable indicator of content validity? Appraisal and recommendations. Research in nursing \& health, 30(4), 459-467.

Righetti, P. L., Dell'Avanzo, M., Grigio, M., \& Nicolini, U. (2005). Maternal/paternal antenatal attachment and fourth-dimensional ultrasound technique: A preliminary report. British Journal of Psychology, 96(1), 129-137.

Sarkadi, A., Kristiansson, R., Oberklaid, F., \& Bremberg, S.(2008). Fathers' involvement and children's developmental outcomes: a systematic review of longitudinal studies. Acta Paediatr, 97(2), 153-8

Schermelleh-Engel, K., Moosbrugger, H., and Müler, H. (2003). Evaluating the fit of structural equation models: Tests of significance and descriptive Goodness-Of-Fit Measures. Methods of Psychological Research Online, 8(2), 23-74.

Şahin F.T., Coşgun A.A., Kılıç, N.A (2017). Babaların çocuklarıyla vakit geçirme durumlarına ilişkin görüşlerinin incelenmesi. GEFAD / GUJGEF 37(1), 319-343

Tavşancıl, E. (2002). Tutumların Ölçülmesi ve SPSS ile Veri Analizi. Ankara: Nobel yayınevi, 1.bask1.

Tinkew, J.B, Carrano, J., Guzman, L.(2006). Resident fathers' perceptions of their roles and links to involvement with infants. Fathering, A Journal of Theory, Research, and Practice about Men as Fathers 4,254-85.

Ustunsoz, A., Guvenc, G., Akyuz, A., \& Oflaz, F. (2010). Comparison of maternal-and paternalfetal attachment in Turkish couples. Midwifery, 26(2), e1-e9.

Xue, W. L., Shorey, S., Wang, W., \& He, H. G. (2018). Fathers' involvement during pregnancy and childbirth: an integrative literature review. Midwifery, 62, 135-14

Yurdugül, H. (2005). Ölçek geliştirme çalışmalarında kapsam geçerliği için kapsam geçerlik indekslerinin kullanılmas1. XIV. Ulusal Eğitim Bilimleri Kongresi, 1, 771-774.

\section{Extended English Summary}

The perception of traditional paternity role in many societies has changed in recent years with social changes. Caregiver roles of fathers have been developing specially in western societies. In Turkish society, fathers now interact more with their children and involve in childcare, education and life.

Father-child relationship affects children's mental and psychological development in the future. However, the interaction of fathers with their children also begins during pregnancy, as in mothers. During pregnancy, fathers also have feelings and thoughts for their babies. In this process, they are more or less attached to their unborn babies and prepare themselves for parenting. During pregnancy, fathers also have feelings and thoughts for their babies. In this process, they are more or less attached to their unborn babies and prepare themselves for parenting. The results of the study regarding the attachment of the father to the fetus during pregnancy are limited. There is a need for more research about paternal prenatal attachment in Turkey. In this context, this study aimed to adapt the "Paternal Antenatal Attachment Questionnaire of Condon (1993) to the Turkish society.

This methodological research was carried out with 155 expectant father who came to a private maternity clinic in Izmir with their partner for routine ultrasound examination between January and June 2018. Individual identification form and Paternal Antenatal Attachment Scale Turkish form were used to collect research data. 
Güleç Şatır, D., \& Kavlak, O. (2021). "Paternal Antenatal Bağlanma Ölçeği” nin Türkçe versiyonunun geçerlik ve güvenirlik çalışması. Journal of Human Sciences, 18(1), 1-11. doi:10.14687/jhs.v18i1.6047

Firstly, permission was obtained from the author who developed the scale by e-mail. Then language validity and content validity of scale were made. Translation and back translation method was used in the language validity. Using the Davis technique for Content Validity, the questions were presented to the opinions of 10 experts and Content validity index of each question was calculated. The scale, which was finalized after language validity and content validity, was applied to 20 expectant father and they were asked to evaluate the clarity and clarity of the questions.

Approval was obtained from the ethics committee of a university to conduct the research. The permission was obtained from the clinic to apply the research. Fathers were informed about the study.

The average age of the fathers included in the study was $32.9 \pm 4.8$ and the average age of marriage was $4.7 \pm 3.7$. The majority of fathers $(51.6 \%)$ are university graduates and the first fathering experience of $38.1 \%$. Scale total scores of fathers included in the study were $64.70 \pm 7.04$ (min: 40, max: 80), total scores of "attachment quality" sub-dimension $28.2 \pm 4.98$ (min: 14, max: 40), "Total time scores for "time spent connecting" sub-dimension were determined as $36,18 \pm$ 3,26 (min: 22, max: 40). Scale total scores of fathers were $64.70 \pm 7.04$ (min: 40, max: 80), total scores of first dimension $28.2 \pm 4.98$ (min: 14, max: 40), and second sub-dimension were determined as 36,18 $\pm 3,26$ ( $\min : 22$, max: 40). When the opinions of 10 experts for the questions in the scale were examined for the content validity, the KGI of each question was found above 0.80 . When the content validity findings are examined; as a result of exploratory factor analysis, it was determined that the scale consists of 2 sub-dimensions. Factor loads varied between 0.84-0.41 in the first dimension and $0.82-0.30$ in the second dimension. It was observed that the factors explained $36.4 \%$ of the variance in total, the percentages of explanation were $26.5 \%$ for factor 1 and $9.9 \%$ for factor 2 . With the confirmatory factor analysis, the scale consisting of 16 items and 2 sub-dimensions was found to be significant at the level of $\mathrm{p}$-value $=0.025$ according to the ChiSquare fit test result. Also, when the goodness of fit indices of the scale are examined RMSEA was 0.044, GFI: 0.912, AGFI: 0.880 and $\chi^{2} / \mathrm{df}$ was $1.298(\mathrm{p}=0.025)$. It shows how suitable the data obtained is for this model. Item total correlations of the scale were found above 0.20 , except for item 8. The item-total correlation of the eighth item was found to be 0.17 . however, the substance was not removed to preserve the original structure. The Cronbach alpha reliability coefficient of the scale was 0.79 , and the Cronbach alpha reliability coefficients of the subscales were 1.78, 2 . subscale: 0.62 .

The scale, which consists of two factors, is valid and reliable for the use of father who are expecting a baby in Turkish society. It is recommended to use the research in order to evaluate the feelings of father, attachment and factors affecting the father during pregnancy. 